Article

\title{
Towards a Fair Distribution Mechanism for Asylum
}

\author{
Philippe van Basshuysen
}

Department of Philosophy, Logic and Scientific Method, London School of Economics and Political Science, Houghton Street, London WC2A 2AE, UK; p.c.van-basshuysen@lse.ac.uk

Received: 31 July 2017; Accepted: 20 September 2017; Published: 25 September 2017

\begin{abstract}
It has been suggested that the distribution of refugees over host countries can be made more fair or efficient if policy makers take into account not only numbers of refugees to be distributed but also the goodness of the matches between refugees and their possible host countries. There are different ways to design distribution mechanisms that incorporate this practice, which opens up a space for normative considerations. In particular, if the mechanism takes countries' or refugees' preferences into account, there may be trade-offs between satisfying their preferences and the number of refugees distributed. This article argues that, in such cases, it is not a reasonable policy to satisfy preferences. Moreover, conditions are given which, if satisfied, prevent the trade-off from occurring. Finally, it is argued that countries should not express preferences over refugees, but rather that priorities for refugees should be imposed, and that fairness beats efficiency in the context of distributing asylum. The framework of matching theory is used to make the arguments precise, but the results are general and relevant for other distribution mechanisms such as the relocations currently in effect in the European Union.
\end{abstract}

Keywords: refugees; distribution mechanism; asylum policy; relocation; market design; matching theory

\section{Introduction}

Recently there has been increasing interest not only in the number of refugees that countries (should) accept, but also in achieving good "matches" between refugees and their host countries. For example, the mechanism for relocating refugees from Greece and Italy to other member states of the European Union (EU) seeks to realise this goal by allowing countries offering relocation to indicate preferences over refugees [1]. Good matches are important because a refugee's international protection needs, and her opportunities to flourish, are served differently in different countries. Moreover, a country's costs for hosting refugees and the public opinion towards them may differ for different types of refugees, which may affect policy makers' willingness to comply with international legal norms [2].

The question of how to distribute asylum amounts to a problem of designing refugee distribution mechanisms according to criteria that may be considered desirable or morally required. Relevant criteria may include maximising the number of places for refugees, fairness, or efficiency considerations. The aim of this paper is to provide some insights into the normative issues that the design of distribution mechanisms raises. One important issue is this: satisfying refugees' or countries' preferences may in some cases reduce the number of refugees matched. It is argued here that there is no simple solution to this problem, and that in instances where a trade-off between the satisfaction of preferences and the number of refugees matched occurs, it is not a reasonable policy to take preferences into account.

On the positive side, we show that a simple sufficient condition can be given which, if satisfied, precludes the trade-off from occurring: that all the countries within the system deem all refugees acceptable, and that all refugees deem all countries acceptable. The latter can only be required if each refugee's rights are respected in each country within the system, rather than in the country she is 
matched to alone. This is interpreted as a precondition that must be satisfied for an asylum policy to reasonably take preferences into account.

Finally, it is argued that, in an appropriate decision framework for asylum, countries should not be allowed to express preferences over groups of refugees in the first place. Instead, priorities over refugees should be imposed according to humanitarian factors such as vulnerability, and according to fairness conditions among the countries within the system. Furthermore, in the context of distributing asylum, the elimination of justified grievance is arguably a weightier normative criterion than efficiency considerations.

In order to make the arguments precise, we draw on tools from game theory. The distribution of asylum is modelled as a (bipartite, many-to-one) matching problem under preferences: refugees and countries offering asylum make up a two-sided market in which the members of one side are to be distributed over members of the other side. Moreover, members of the market have preferences over or may give priority to members of the other side of the market, the satisfaction of which makes for the goodness of the matchings. Formulating the asylum market in this way allows us to use tools from matching theory to provide a more precise understanding, and may eventually contribute to the implementation of more fair or efficient policies. Various social scientists have recently argued for imposing centralised matching systems and have investigated mechanisms that could be implemented in different stages of distributing asylum seekers [3-10]. While we are sympathetic to this line of research, this paper does not directly contribute to it. Rather, it serves as a commentary on normative issues that typically arise in this context.

The remainder of the paper is organised as follows. In the next Section 2, our main case study is introduced: the relocation mechanism that is currently in effect in the EU. The case study naturally suggests three desiderata on the distribution of refugees that are made precise in Section 3 through a simple model from matching theory: the College Admissions model. A mechanism that takes preferences into account is shown to achieve some of the desiderata, but it is then shown that there may be trade-offs between the desiderata, and so a condition is given to prevent these trade-offs from occurring. In Section 4, it is shown that the College Admissions model violates the last desideratum encountered in Section 2: it opens the door to discriminatory policies and unduly favours popular countries at the expense of less popular ones. This motivates modelling the asylum market as a School Choice problem. This model is described in Section 5, where it is argued that fairness beats efficiency in the context of distributing asylum. Section 6 provides the conclusions.

\section{Desiderata on the Distribution of Refugees: The EU Relocation Mechanism}

To prevent terminological confusion, let refugee denote a recognised refugee or an asylum seeker with a justified claim to refugee status. ${ }^{1}$ We are concerned with their distribution on a supranational scale: refugees are to be distributed over a given set of nation states (henceforth 'countries') which—voluntarily or enforced by a superordinate (con)federation government-agree to be possible host destinations. The distribution problem may either occur in the context of resettlements: the distribution of refugees from third countries or refugee camps among the countries in the system; or in the context of relocations: the redistribution of refugees already in a country in the system.

The context determines the number of refugees in the system. This can be a target set by a superordinate institution (such as the EU's target to relocate a certain number of refugees), or the sum of pledges made by the countries within the system (such as some EU member states' pledges to resettle a certain number of refugees). Moreover, there may be (although there need not be) quotas: numbers of refugees that countries will accept. These numbers may either be individual pledges

1 This presupposes a consistent definition of what counts as a justified claim (at least among the countries within the system), which is a controversial issue (see [11]). For simplicity, this problem will be ignored except for a short discussion in Section 5 . 
made by the countries, imposed according to a distribution key [12,13], or the outcome of a market of tradeable immigration quotas [3].

Let us take a concrete distribution problem as a case study. In September 2015, the European Commission proposed a mechanism for the relocation of refugees from Greece and Italy among EU member states. The proposal shows awareness of the importance of good "matches" between refugees and countries of relocation:

"[I]n order to decide which specific Member State should be the Member State of relocation, a specific account should be given to the specific qualifications and characteristics of the applicants concerned, such as their language skills and other individual indications based on demonstrated family, cultural or social ties that could facilitate their integration into the Member State of relocation." [1]

Subsequently, the Council adopted the proposal in a decision on a temporary relocation of 160,000 asylum seekers in clear need of international protection from Greece and Italy [14,15]. In order to comply with the target of achieving good matches, the relocation mechanism allows member states of relocation to indicate preferences over refugees who applied for relocation. Greek and Italian authorities then choose among applicants and thereby "try as much as possible to meet the preferences expressed" [15]. After determining the matches, they send relocation requests to the countries, which are legally binding.

The relocations are not running smoothly. Three problems are particularly noticeable. First, there seems to be considerable discontent with some matches. Many refugees have disappeared after learning about the decision on their destination country [16]. Others have vanished after their relocation, and preventing such irregular secondary movements has become a central policy goal [14,17]; second, the number of refugees distributed lags far behind the policy target. By July 2016, almost a year after the Commission's proposal had been adopted, the total number of persons relocated equalled only 3056 , which corresponds to less than $2 \%$ of the 160,000 people envisaged [18]. As of July 2017, the mechanism seems to have gained some traction but still less than 25,000 refugees have been relocated [19]; third, the preferences some countries express are ethically problematic and in conflict with the EU's policy goals. For example, although the Council appealed to the member states to give priority to particularly vulnerable persons (e.g., unaccompanied minors, pregnant women, disabled and elderly persons), some member states are reluctant to receive persons from these groups [16]. Furthermore, although legally required to accept all types of refugees, some member states have rejected allocations on the grounds that their preferences were not respected [16].

The problems with the EU relocation mechanism motivate three desiderata on asylum matchings that will be adopted in this discussion. First, available places should be used efficiently (in a sense to be specified). Roughly, the refugees' or countries' preferences should be satisfied "as much as possible", in particular in order to minimise refugees' incentives to vanish or partake in secondary movements; second, the number of refugees matched should be maximised and should possibly equal the policy goal; third, the system should ban an "incorrect use of preferences" [16]: preferences should be expressed in line with fundamental ethical principles and higher-order policy goals.

The desiderata can be defined precisely within the framework of matching theory, which shall be introduced next.

\section{Asylum as College Admissions Problem}

Matching under preferences is a tool from cooperative game theory. It can be applied to two-sided markets in which heterogeneous agents, or goods, of one side are to be distributed over agents or goods of the other side of the market, and the satisfaction of agents' preferences, or respect for agents' priorities, matter. Gale and Shapley [20] laid the theoretical foundations for the theory. Centralised matching systems have since been implemented in different contexts such as matching students to universities, job-seekers to employment, or kidney donors to patients. 
Various economists and political scientists have argued that implementing a matching system in the context of asylum would be beneficial for refugees, or their possible host countries. Fernández-Huertas Moraga and Rapoport [3-5] use a matching system embedded in the tradeable immigration quotas system they propose for, among other things, the distribution of refugees over EU countries. Furthermore, Jones and Teytelboym advertise the implementation of matching systems both on a local [6] and on a global [7] scale. Delacrétaz, Kominers and Teytelboym [9] propose specific mechanisms for locally matching refugees with communities in different institutional and informational settings; and Andersson and Ehlers [10] design a matching system in the context of assigning private housing to refugees in Sweden.

Rather than argue for a specific matching system, or matching systems generally, our interest here is to show that matching theory yields insights that are important for the ethics of asylum distribution. The main difference between the EU's relocation mechanism and a centralised matching system is that, in the latter, the matchings are determined through the application of a mechanical procedure. The resulting matchings can be compared along the same properties, however, and thus the desiderata within the framework of matching theory and the theoretical results hold equally for contexts such as the relocations in the EU.

Fernández-Huertas Moraga and Rapoport [3] propose implementing a College Admissions (CA) model on the asylum market. This model resembles our case study in that it takes into account the preferences countries have over (groups of) refugees, which is why it serves as a natural starting point. It differs from the case study in that members of either side of the market are equally treated as agents with preferences over members of the other side of the market: countries have preferences over refugees and refugees have preferences over countries, which is why the CA model allows for more general mechanisms than the EU's relocation mechanism which only takes countries' preferences into account. A matching affects the countries' and refugees' welfare relative to the satisfaction of their preferences.

Formally, ${ }^{2}$ a CA-instance of a refugee-country matching problem is a four-tuple $(C, R, q, \boldsymbol{P})$, where $C=\left\{c_{1}, \ldots, c_{m}\right\}$ and $R=\left\{r_{1}, \ldots, r_{n}\right\}$ are disjoint sets of $m$ countries and $n$ refugees, respectively. The agents of the market are the members $a_{k} \in R \cup C$. We are concerned with many-to-one matchings since it can be assumed that $n \gg m$ and each refugee can obtain asylum in at most one country, whereas a given country can accept many refugees. The maximum number of refugees that can be matched to each country is determined by a vector of quotas $q=\left(q_{j}\right)_{j \in\{1, \ldots, m\}} \in \mathbb{N}^{m}$. As described in the previous section, quotas may be imposed according to a distribution key, the outcome in a market of tradeable immigration quotas, or may be individually set by the countries; or there may be no real quotas at all: setting $q_{j}=n$ for all $c_{j} \in C$ makes them dummies. Finally, $\boldsymbol{P}=\left\{P\left(c_{1}\right), \ldots, P\left(c_{m}\right), P\left(r_{1}\right), \ldots, P\left(r_{n}\right)\right\}$ is a set of preference lists which induces a complete, transitive, and irreflexive preference profile for each country over the set of refugees and for each refugee over the set of countries. Write $c_{1} \succ_{r_{i}} c_{2}$ to denote that $r_{i}$ prefers $c_{1}$ to $c_{2}$, and equivalently for countries' preferences.

Refugees may declare countries unacceptable, and countries may declare refugees unacceptable. Hence, there is a subset $E \subseteq R \times C$ of acceptable refugee-country pairs. Denote $A\left(r_{i}\right)=\left\{c_{j} \mid\left(r_{i}, c_{j}\right) \in E\right\}$ the set of acceptable countries for a given $r_{i} \in R$; and equivalently for the countries.

An assignment $M$ is a subset of $E$, and the set of assignees for a given $a_{k} \in R \cup C$ is denoted $M\left(a_{k}\right)$. A refugee $r_{i}$ can be unassigned so $M\left(r_{i}\right)=\varnothing$, or otherwise assigned. Similarly, a country $c_{j}$ is undersubscribed if $\left|M\left(c_{j}\right)\right|<q_{j}$, and full if $\left|M\left(c_{j}\right)\right|=q_{j}$.

Definition 1 (Matching). A matching is an assignment with

(i) $\left|M\left(r_{i}\right)\right| \leq 1$ for all $r_{i} \in R$; and

(ii) $\left|M\left(c_{j}\right)\right| \leq q_{j}$ for all $c_{j} \in C$. 
According to (i), a given refugee is either assigned to a single country or unassigned under a matching. As usual in the literature, $M\left(r_{i}\right)$ may be used sloppily to refer to the country to which $r_{i}$ is matched instead of the singleton containing that country, whenever this does not cause confusion.

What (ii) says is that a given country accepts a subset of the set of refugees, the cardinality of which is restricted by the country's quota. In the following, say equivalently that $r_{i}$ is matched to $c_{j}$ and that $c_{j}$ is matched to $r_{i}$ under $M$ if $\left(r_{i}, c_{j}\right) \in M$.

\subsection{Stability and Deferred Acceptance Algorithms}

We can now turn to the desiderata encountered in the previous section. It will be argued that the desideratum that preferences be satisfied "as much as possible" amounts to stability (ST) in the CA model. We shall first define this property and introduce an algorithm that produces matchings that satisfy (ST).

A matching $M$ is blocked by a refugee-country pair $\left(r_{i}, c_{j}\right) \in E \backslash M$ if $r_{i}$ is unassigned in $M$ or prefers $c_{j}$ to $M\left(r_{i}\right)$, and at the same time $c_{j}$ is undersubscribed in $M$ or prefers $r_{i}$ to a member of $M\left(c_{j}\right)$. A matching satisfies (ST) if it is not blocked by any refugee-country pair.

Deferred acceptance algorithms produce matchings that satisfy (ST) for each CA-instance [20]; in the following, call such mechanisms stable. Consider the following "country-proposing deferred acceptance algorithm", $\mu^{\mathrm{C}}$ :

- In the first step, each country proposes its most preferred acceptable refugees until its quota is

filled. Each refugee tentatively accepts her most preferred country among the acceptable proposers and rejects the other proposers.

- In the second step, each undersubscribed country proposes to the next best preferred acceptable refugees to whom it has not yet proposed until its quota is filled. Each refugee tentatively accepts her most preferred country among the acceptable proposers and the country she tentatively accepted in the previous step, and rejects the other proposers.

- The process is repeated until there are no more proposals. ${ }^{3}$

The ending condition applies when either all refugees are matched, or all countries are full, or there are unmatched refugees and undersubscribed countries but all such agents are deemed unacceptable by the remaining partners they find acceptable. For an illustration of the algorithm, consider a small CA-instance.

Example 1. There are three refugees, $r_{1}, r_{2}, r_{3}$, and two countries $c_{1}, c_{2}$ with $q_{1}=2$ and $q_{2}=1$. The preference relations are as specified in Table 1.

Table 1. Table specifying refugees' and countries' preferences for Example 1. $a \succ_{c} b$ denotes that $c$ strictly prefers $a$ to $b$.

\begin{tabular}{c|c}
\hline Countries & Refugees \\
\hline$r_{1} \succ_{c_{1}} r_{2} \succ_{c_{1}} r_{3}$ & $c_{2} \succ c_{1}$ for both $r_{1}$ and $r_{2}$ \\
$r_{2} \succ_{c_{2}} r_{1} \succ_{c_{2}} r_{3}$ & $r_{3}$ declares only $c_{2}$ acceptable \\
\hline
\end{tabular}

3 We must add two qualifications. First, $\mu^{\mathrm{C}}$ is a simple algorithm which is not fit for purpose. For example, it cannot accommodate the fact that many refugees flee as couples or in families that should not be separated. It is nevertheless introduced in order to make clear the ethical problem that the size and the "quality" of matchings can be in conflict-a problem which is present in more complex algorithms (e.g., [9]). Second, $\mu^{C}$ is not the only stable mechanism. The reason it is presented here is that it is the deferred acceptance algorithm which is arguably closest to implementing the mechanism used in the EU relocations in which the countries "pick" refugees according to their preferences. But whereas $\mu^{C}$ also respects the refugees' preferences, they are not taken into consideration in the EU mechanism. Whether a countryor a refugee-proposing deferred acceptance algorithm is preferable is debatable as both have pros and cons (for example, Ref. [3] proposes $\mu^{C}$, whereas Ref. [7] prefers a refugee-proposing algorithm). For our purposes, nothing hinges on this question and our arguments in the following hold equally for other deferred acceptance algorithms. 
Apply $\mu^{C}$. In the first step, $c_{1}$ proposes to $r_{1}$ and $r_{2}$, and $c_{2}$ proposes to $r_{2} . r_{2}$ tentatively accepts $c_{2}$ and rejects $c_{1}$, and $r_{1}$ tentatively accepts $c_{1}$. $c_{1}$ has a free place. In the second step, $c_{1}$ proposes to $r_{3}$ and $r_{3}$ rejects. $c_{1}$ has a free place but no more refugees to propose to so the algorithm stops. The resulting matching is $\left(\left(c_{1}, r_{1}\right),\left(c_{2}, r_{2}\right)\right)$.

It can easily be checked that the matching is stable. For example, $r_{1}$ prefers $c_{2}$ to her actual match, $c_{1}$. However, $c_{2}$ does not form a blocking pair with $r_{1}$ because it is full and prefers its actual match to $r_{1}$. Similarly for the unmatched $r_{3}$.

Why does (ST) in the CA model amount to satisfying preferences "as much as possible"? First, it implies Pareto efficiency in the CA model: agents could only be made better off by making other agents worse off. (It can easily be verified that this is true in the above example.)

Second, a distribution that satisfies (ST) can be considered to be fair in the following sense. Only if $c_{2}$ had free places available or preferred $r_{1}$ to its actual match would $r_{1}$ have a justified claim to be matched to $c_{2}$, but this is ruled out because the matching is stable. This lack of justified claims is what makes for a fair distribution. Note that this condition may not be sufficient for eliminating all discontent with the matchings: it does not imply that all agents get what they want most (which is usually impossible, see Example 1). It only implies that they are matched to an acceptable partner and that they are not matched to a less preferred partner when a more preferred partner would be available.

Third, the sense of fairness (ST) conveys can be expected to contribute to the thickness of the market: it gives agents on both sides incentives to participate in the system. Conversely, if (ST) is violated, both sides of the market may be dissatisfied. There is ample evidence that in many contexts, agents seek to arrange bilateral arrangements outside the system when this happens (e.g., in the context of matching doctors with hospitals [22-24]). Note that the EU relocation mechanism violates (ST) in a specific way: it does not systematically take refugees' preferences into account, thus resulting in matchings that can be considered unfair for refugees. In this context, it may be difficult for refugees to arrange bilateral arrangements outside the system. Nevertheless, the failure to take their preferences into account may contribute to the finding from the previous section that many vanish after learning about their destination countries, or partake in illegal secondary movements.

\subsection{Maximum Cardinality vs. Stability}

Consider now the next desideratum encountered in Section 2. Call the number of refugees assigned in a matching its cardinality. The cardinality of a matching depends on the set of acceptable refugee-country pairs, i.e., the set $E \subseteq R \times C .{ }^{4}$ Call maximum cardinality (MC) the desideratum that matchings should not waste places. More precisely, for a given CA-instance, a matching $M$ satisfies (MC) if and only if $|M| \geq\left|M^{\prime}\right|$ for all matchings $M^{\prime}$.

In Example 1 above, $\left(\left(c_{1}, r_{1}\right),\left(c_{1}, r_{2}\right),\left(c_{2}, r_{3}\right)\right)$ is the unique maximum cardinality matching. It is not stable because $\left(c_{2}, r_{1}\right)$ and $\left(c_{2}, r_{2}\right)$ are blocking pairs: both $r_{1}$ and $r_{2}$ prefer $c_{2}$ to $c_{1}$, and at the same time $c_{2}$ prefers both $r_{1}$ and $r_{2}$ to $r_{3}$. In contrast, remember that applying $\mu^{C}$ produced the stable matching $\left(\left(c_{1}, r_{1}\right),\left(c_{2}, r_{2}\right)\right)$, leaving $r_{3}$ unmatched and $c_{1}$ undersubscribed. Thus, satisfying (ST) comes at the price of failing to satisfy (MC).

The fact that (MC) and (ST) may conflict poses a problem because both (MC) and (ST) have normative appeal. In many contexts where matching theory is applied, (ST) is the primary policy goal, and there is some loss in the size of the matchings allowed for because it can be compensated through

4 The cardinality of matchings also crucially depends on countries' quotas which are taken as exogenous variables here. In passing, note that in contexts in which countries state voluntary quotas the application of deferred acceptance algorithms is problematic because they generate incentives to capacity-manipulate: countries may gain by stating smaller quotas. As shown in [25], there is no stable mechanism that is immune to capacity-manipulation. Hence, $\mu^{C}$ combined with voluntary quotas would incentivise countries to enter a race of diminishing their stated capacities—which is an extremely undesirable consequence for a good in short supply, and may serve as an argument against voluntary quotas. 
different instruments from market design. Two such instruments shall be discussed briefly and shown to be inadequate in the context of the asylum market. This suggests that there is no simple resolution to the problem.

First, in the matching markets for medical residents or for new economists, so-called "scrambles" have been established for unmatched and undersubscribed agents. These are decentralised post-match markets where available agents of both sides of the market can find each other and positions can be filled [26]. However, the fundamental difference between matching asylum and contexts where matching theory is usually applied is that in those contexts, both sides of the market have incentives to fill available places. In the context of asylum, many countries have opposite incentives, and few countries not filling their quotas would advertise this in a scramble. A scramble is thus unlikely to be efficient or even to emerge in the first place.

Second, countries unable to fill their quotas may be penalised. ${ }^{5}$ Penalties are often difficult to impose, however, even when countries' participation in a relocation mechanism is obligatory. In the EU context, for example, it has been proposed that countries not filling their quotas pay a fine of 250,000 Euros for every assigned place that remains empty. What the prospects are for this proposal is questionable, however, as various countries, most notably members of the Visegrad Group, are virtually boycotting the relocations. Moreover, Hungary and Slovakia took legal steps against the relocations and refused to accept any more refugees before a verdict would be announced [27]. The European Court of Justice dismissed the suit on September 6 [28], but Hungary's prime minister declared that this won't change Hungary's policy of not participating in relocations [29]. While it may be possible to penalise Hungary for not complying with the EU regulations in the future, the process can be expected to be long and politically tedious.

Besides worries about the prospects for implementing penalties, note that they may make the system manipulable for the refugees: it may pay to be "picky". This is the case when the revenues from the penalties are used to provide more asylum places elsewhere, thus in the best case satisfying (MC). In Example 1, applying $\mu^{C}, r_{1}$ gets assigned to her least preferred country, $c_{1}$. Now, suppose that for each place that remains empty, $c_{1}$ is penalised and with the help of the penalty, a place is created elsewhere. If $r_{1}$ prefers a place elsewhere to $c_{1}$, she would gain by declaring $c_{1}$ unacceptable even though she finds it acceptable. Although these are not definite reasons for the intractability of imposing penalties, they do suggest some caution: imposing penalties may be difficult, and may lead to undesirable incentive structures. Since these issues do not seem to have a definite solution at present, penalties will be neglected in the following. ${ }^{6}$

Whenever (ST) and (MC) are in conflict, we must bite the bullet and give up one of the desiderata. Which one? Consider again Example 1. Suppose $r_{3}$ is justified in declaring $c_{1}$ unacceptable. For example, she may belong to an ethnic or religious group that is persecuted in $c_{1}$ (and suppose $r_{1}$ and $r_{2}$ do not belong to such a group). Refugee $r_{3}$ is then in a particularly disadvantaged situation because she cannot expect protection in one of the countries within the system. By assigning her to the acceptable country $c_{2}$, the maximum matching gives priority to $r_{3}$. Since priority is given to the

5 Penalties are proposed in [3] in the context of a market of tradeable immigration quotas, where the penalty is a function of the difference of the quota negotiated and the number of refugees assigned to the country under $\mu^{C}$.

6 For more arguments against penalties, cf. [7]. A third resort to fix the problem is to internalise it in the matching system by imposing minimum quotas. This strategy is not relevant here because the context of asylum is different to the setting where minimum quotas are usually investigated. For example, Fragiadakis, D., et al. [30] investigate minimum quotas in the context of school choice. They assume that all schools are acceptable to all students and vice versa, and look at the case where the number of students is strictly between the sum of the schools' minimum quotas and the sum of the schools' maximum quotas. In the case where the number of students exceeds the number of places available-which is to be expected in the context of asylum-minimum quotas are dummies in this setting. In contrast, the problem we are concerned with is the case in which places may be wasted due to size of the set of acceptable refugee-country pairs. The special case where students may declare schools unacceptable is considered in [30], but their mechanisms allow violating minimum quotas and don't satisfy (MC). 
worst-off, (MC) could be interpreted as a prioritarianist condition [31,32]. It is moreover a condition that the Rawlsian maximin principle [33] would embrace.

Giving priority to the worst-off may come at the cost of making other agents in the market worse off. In the example, $r_{2}$ and $c_{2}$ are worse-off in the maximum matching than in the stable matching. As we have seen, (ST) implies Pareto efficiency in the CA model, and has been interpreted in this model as the desideratum that agents' preferences should be satisfied "as much as possible". Thus, in contrast to (MC), (ST) in the CA model can be approximately characterised as "utilitarian" (e.g., [34]). ${ }^{7}$

Which condition should be prioritised? Arguably, in the context of asylum in which by definition, people are in disadvantaged and vulnerable situations, it is a more reasonable policy to give priority to the worst-off. There is empirical evidence that this agrees with a widespread intuition in many receiving countries [2]. This suggests that satisfying preferences is not a reasonable policy in instances in which it violates maximum cardinality.

A second reason for giving priority to (MC) over (ST) is that asylum is a public good and is as such in constant short supply [3]. For example, remember that the total number of persons relocated in the EU up to July 2016 was less than $2 \%$ of the 160,000 people envisaged [16]. On a larger scale, the UN Refugee Agency [35] estimates the projected global resettlement needs in 2017 more than seven times higher (over 1.19 million) than the sum of the expected global quotas from resettlement countries $(170,000)$. The gap between demand and supply is so blatant that the desideratum to bring many refugees into a safe harbour trumps the desideratum to satisfy "as much as possible" the preferences of fewer.

\subsection{When Preferences Can Be Taken into Account}

It is also possible to investigate the conditions under which (ST) and (MC) are jointly satisfied. For example, Andersson and Ehlers [10] design a mechanism that produces maximum stable matchings for assigning refugee families to landlords in Sweden. In that context, maximum stable matchings exists because refugees' and landlords' preferences only range over common languages spoken and the sizes of families, and are assumed to be correlated in a specific way. In the present context of distributing refugees over countries, preference structures are more complex. However, a simple sufficient condition can be given: note that (ST) and (MC) conflict only if some countries deem some refugees unacceptable, or if some refugees deem some countries unacceptable. Recall that $E \subseteq R \times C$ denotes the set of acceptable refugee-country pairs, so that $E=R \times C$ indicates that everyone finds everyone acceptable. Then, we have the following simple fact.

Proposition 1. In $C A$-instances in which $E=R \times C$, stable maximum matchings exist.

Proof of Proposition. Suppose $E=R \times C$ in a given CA-instance. It can be shown that the stable mechanism $\mu^{C}$ provides a maximum matching. Applying $\mu^{C}$, a refugee $r_{i}$ accepts any country $c_{j}$ 's proposal in a step $n$ unless in some step up to $n$, a preferred country has proposed to $r_{i}$. Recall that $q_{j}$ denotes country j's quota. There are two cases to consider. First, suppose there are more places than refugees, i.e., $|R|<\sum_{k=1}^{m} q_{k}$. Each refugee who gets a proposal at some point will get matched because she only rejects if she already has a better offer. However, each refugee gets a proposal at some point because $E=R \times C$. Thus, the resulting matching $M$ has a cardinality equal to the number of refugees, $|M|=|R|$, and so $M$ is maximum. Second, suppose the number of refugees exceeds or equals the sum of all quotas, i.e., $|R| \geq \sum_{k=1}^{m} q_{k}$. Because $E=R \times C$ every country will fill its quota, and $|M|=\sum_{k=1}^{m} q_{k}$. Hence, $M$ is again maximum.

7 This is not a precise characterisation because the matching framework introduced here does not allow for cardinal utilities which are required for utilitarianism to be a meaningful doctrine. The labelling as "utilitarian" is a mere approximation. 
Although this is a very simple fact, it leads to interesting moral considerations. Can we require as a policy that every country deems every refugee acceptable and vice versa? The former is the case in the context of the EU's relocation mechanism: member states are required to accept all types of refugees, not only those on their preference lists ([14]). ${ }^{8}$ The reason this is required is that unilaterally declaring groups of refugees unacceptable may open the door to discriminatory policies. Moreover, it would allow countries to "play dummy": by stating a small or empty preference list, countries could participate in the system without fulfilling their quotas. It is reported in [16] that this has indeed happened in the context of relocations in the EU—although it is an illegal practice-and that member states are urged to refrain from it. Thus, for the initiators of the EU relocation mechanism, it seems uncontroversial that countries must accept all types of refugees, and the problem is rather to enforce this rule. However this may be enforced in practice, the CA model must be modified by imposing the restriction that the countries' preference profiles range over the whole set of refugees; formally, $A\left(c_{j}\right)=R$ for all $c_{j} \in C$.

To require that all refugees deem all countries acceptable is more problematic. As shown in the above example, if it is to be expected that in a given country the rights of a certain group of refugees are violated, then refugees who belong to this group can justifiably refuse to go there. Reasons for justified refusal include denial of non-discriminatory access to national services and public goods.

However, if it is the case that in each country within the system all refugees' rights are respected, refugees can be expected to deem all countries acceptable. Suppose the sum of the available places equals the number of refugees within the system. The following may then be considered a condition of fairness: a given refugee gets matched if she declares all countries acceptable. (The proof is a trivial extension of the proposition above.) In other words, if a refugee is willing to be matched with any country within the system she is guaranteed a place. This fairness condition agrees with the European Commission's proposal where refugees' successful applications to the relocation scheme do not imply a choice as to which country they move but do imply a relocation [16].

To sum up, if refugees' rights are respected in each country within the system, then it can be required that "everyone finds everyone acceptable", which guarantees that (ST) and (MC) can jointly be satisfied. However, whenever the set of countries includes a country where some minorities' rights are violated-although for other groups it may be a safe harbour-refugees that belong to these minorities cannot be expected to deem that country acceptable. (ST) should then be given up: in such instances, it is not a reasonable policy to take preferences into account. The trade-off between (ST) and (MC) can thus be interpreted as delimiting the area where preference satisfaction is a desirable policy goal. In the remainder of this article, it is assumed that the condition of no rights violations is met, and thus that a maximum stable matching exists.

\section{Compliance with Higher-Order Policy Goals and Ethical Principles}

In this section, it is argued that, even if the requirement of no rights violation is met and a modified CA model adopted in which "everyone finds everyone acceptable", this model must be rejected. The reason is that the CA model conflicts with the third desideratum encountered in Section 2: that the system should ban the possibility of "incorrect use of preferences" [16]. An "incorrect use of preferences" is an expression of preferences which are in conflict with higher-order policy goals or ethical principles. Call this desideratum on the system compliance (COM). Compliance is also violated if agents can "game the system", i.e., achieve a more preferred matching by handing in preference lists strategically. It is a well-known result in matching theory that no stable mechanism is strategy-proof in the CA model [36]. In the following, two additional lines will be discussed along which (COM) is

8 Cf. "Member States retain the right to refuse to relocate an applicant only where there are reasonable grounds for regarding him or her as a danger to their national security or public order", and: "Member States of relocation...should be ready to welcome all types of migrants (families, unaccompanied minors, single male applicants)." [14]. 
violated in the CA model: the model enables the expression of impermissible preferences; and popular countries may be unduly favoured at the expense of less popular countries.

\subsection{Impermissible Preferences of the Countries}

So far, a model has been assumed in which countries have strict and complete preferences over refugees. In practice, since the number of refugees may be large, countries cannot give strict preference lists over refugees. Rather, countries have preferences over groups of refugees that are identified through a classification according to properties the countries are interested in, for example profession, languages spoken, family status, urgency, etc. Suppose such a classification system is available. Countries are then indifferent between members of one and the same group, and a tiebreaker must be applied in order for the system to work. ${ }^{9}$

The task of designing a feasible classification system immediately gives rise to ethical problems: what properties of refugees can permissibly figure in countries' preferences? It has been argued that immigrants should generally not be selected on grounds of ethnicity, and that countries' preferences should be restricted to range over "neutral" properties such as particular skills [39]. This principle should arguably also be applied in the context of asylum. It also agrees with the EU's relocation mechanism, which allows member states to express their preferences over refugees, albeit with "due respect of the principle of non-discrimination" [1].

It is, however, hardly possible to entirely ban the use of ethically impermissible preferences in the CA model if there are countries in the system with such preferences. Restrictions can be imposed on the classification system-e.g., that preferences along ethnicity be forbidden. However, ethnicities also determine other features that are present in any reasonable classification system, such as mother tongue. Correlations between different such factors may make it possible to game the system, thereby violating $(\mathrm{COM}) .^{10}$

Even if it is possible to design a classification system that cannot be manipulated in this way, countries' preferences may still conflict with ethical principles and higher-order policy goals. The EU relocation mechanism provides plenty of evidence. For example, Commission [16] urges countries to express preferences in line with the policy goal "to facilitate integration of the relocated person in the Member State of relocation". However, "the majority of Member States use the preferences as a means to exclude possible candidates rather than to allow for a better matching process for better integration". As a consequence, it is demanded that "Member States of relocation should limit to the extent possible the preferences expressed" (ibid.). However, this stands in stark contrast to the rules of the relocation mechanism, which allow countries to express preferences in order to achieve good matches. It also stands in contrast to the CA model.

\subsection{Unequal Treatment of Countries}

Another important policy goal in the EU's relocation mechanism is to achieve equal treatment of countries. For example, concerning particularly vulnerable applicants, the Council urges "the necessity of ensuring a fair distribution of those applicants among Member States" [14]. Equal treatment of countries is desirable both for fairness considerations and because it may be practically infeasible to impose a system in which some countries are worse off than others. If the system cannot ban the

9 This is usually a randomisation device, which has problematic consequences. For some strict CA-instances obtained by breaking the ties the matchings produced by deferred acceptance algorithms may be Pareto dominated for the refugees by others. The algorithms may be modified to solve for Pareto efficient matchings but only at the cost of strategy-proofness [37,38]. This may pose a problem in practice; for simplicity, it will not figure in the arguments given here.

10 Miller [39] excludes this on grounds of "good faith". However, as regards asylum, good faith is a weak hope to rely on in reality, particularly considering that many EU countries have not complied with their humanitarian responsibilities during the refugee crisis [40]. 
expression of preferences that leads to unequal treatment of countries, then there is a violation of (COM). However, the CA model may violate (COM) in this respect, in the following way.

In a usual asylum market, there are more and less popular countries for large proportions of refugees, i.e., their preferences are correlated. If refugees' preference relations are sufficiently homogeneous, then deferred acceptance algorithms (and hence $\mu^{\mathrm{C}}$ ) in the CA model show favouritism to the most popular countries. For example, suppose there are two countries, $\mathrm{HI}$ and $L O$, and 100 refugees $r_{1}, \ldots, r_{100}$, all of whom prefer HI to LO. Applying $\mu^{C}, H I$ can "cherry-pick" its favourite group of refugees until its quota is satisfied. The problem is that $L O^{\prime}$ s preferences are not at all taken into account: under any possible preference list, it will be assigned the same refugees. Moreover, it implies a practical problem: why should $L O$ be willing to join the system? However, if countries that consider themselves on the "losing side" are discouraged from participating in the system, this may produce a market that is too short on the supply side if participation is voluntary, or no market at all if they are co-policy setters with sufficient weight.

Are refugees' preferences really so homogeneous that popular countries would be shown favouritism at the expense of unpopular countries? This question has not been answered conclusively. First of all, it is not clear how to set the threshold of when unacceptable favouritism begins. However, even if this is settled, so far not much data have been collected as to the actual preferences of refugees, and it is difficult to infer from the total or relative numbers of past asylum applications in a given country to the popularity of that country; for asylum seekers may not have had a choice in where to apply for asylum. It seems a risky policy to implement a system in which popular countries are shown favouritism if refugees' preferences are homogeneous given that it is an open question whether their preferences are indeed too homogeneous.

Furthermore, there are indicators suggesting that refugees' preferences are relatively homogeneous. Two of the most important factors that shape refugees' preferences are family and diaspora in a country (e.g., [41]; on a local level also [42]). These factors agglomerate the preferences of a population of refugees from a given country or region and make them more homogeneous than those of populations from different countries or regions. The fact that the main population of current asylum seekers is centred on few countries ${ }^{11}$ may be evidence that their preference relations are relatively homogeneous.

It has been argued in [7] that one can turn the tables on homogeneity of preferences. The risk of homogeneity may have positive effects on the market, so the argument goes, because countries will have incentives to court refugees in order to become popular destinations. This, however, seems to be an overly optimistic claim. A country may be unattractive for reasons that cannot be eliminated by changing its incentives-particularly, economic reasons. It seems that this country would then be unjustly disadvantaged in the CA model, if refugees' preferences are homogeneously biased against it. Moreover, the argument does not address the problem that the market may not even come into existence if states are not interested in "courting" refugees, especially if they consider themselves on the losing side as a consequence of past deterrence of refugees.

Moreover, the incentives argument can be turned around. As discussed in the previous section, refugees can be expected to deem a country acceptable only if their rights are respected there. However, a country interested in diminishing the number of refugees matched to it may have incentives to deter them from coming through drastic messages, or even to violate the rights of refugees already in the country in order to achieve this goal. Such policies are in effect in various countries all over the world, ${ }^{12}$ and the fact that the CA model may enforce the incentives for such policies casts doubt on its normative desirability and effective operation.

11 In 2015, almost one out of three first time asylum seekers entering the EU originated from Syria, followed by Afghanistan $(14 \%)$ and Iraq $(11 \%)[43,44]$.

12 For example, Hungary has been accused of criminalising and thereby violating refugees' rights, e.g., [45,46]. Similar reproaches have been addressed to Australia, e.g., [47]. 
Summing up, the CA model not only makes it difficult to prevent discriminatory policies. It also likely disadvantages some countries at the expense of others, thus provoking inequality among the countries and yielding undesirable incentive structures. The CA model violates (COM) in these respects, and, arguably, this is sufficient reason to reject the CA model for the asylum market.

\section{Asylum as School Choice Problem}

In the previous section, we encountered two lines along which the CA model violates (COM). First, even if the classification of refugees is restricted to "neutral" properties, it cannot be ruled out that some countries are manipulating the system by "incorrectly" expressing preferences [16]. Second, popular countries' preferences likely receive overproportional weight at the expense of less popular countries.

What drives both problems is that countries are allowed to state preferences over groups of refugees. This motivates the following modification of the system. Refugees' preferences are taken into account, as before. However, countries are not considered economic agents with preferences over the people they provide with asylum; instead, asylum in a country is an object to be consumed by an asylum seeker. It is an object in short supply, but at the same time, it would be repugnant to sell it on a free market, in the sense of [48]: many people think such transactions should not occur even if agents in the market would voluntarily engage in them.

How should asylum be distributed, if not through a free market? Arguably, a country should give its available places to the applicants who need it most or would most profit from it. This may be determined through priorities for certain features of refugees. Priorities may comprise features such as vulnerability, urgency, dependants in a country, languages spoken, specific skills, etc. (these examples are policy goals set by the Council $[14,15])$. Criteria for setting priorities must be commonly agreed on, plausibly in conformance with a supranational institution such as the European Parliament, and should comprise only "neutral" properties. For example, a country could be allowed to prioritise refugees who speak its language but should not be allowed to prioritise race [7]. National governments could then determine which features to prioritise while respecting the criteria agreed on.

In terms of matching theory, this suggests modelling asylum as a School Choice (SC) problem. The SC model was developed for the assignment of pupils to public schools in US school districts. In this context, schools are not assumed to be strategic agents, and it is only the pupils' welfare that matters [49]. Formally, the SC model can be attained from the CA model by restricting the set of preference lists to the refugees, and defining priority lists for the countries. Thus, an SC instance of a refugee-country matching problem is a five-tuple $(R, C, q, \boldsymbol{P}, \boldsymbol{P r} \boldsymbol{i})$ with $\boldsymbol{P}=\left\{P\left(r_{1}\right), \ldots, P\left(r_{n}\right)\right\}$, and where $\operatorname{Pr} \boldsymbol{i}=\left\{\operatorname{Pri}\left(c_{1}\right), \ldots, \operatorname{Pri}\left(c_{m}\right)\right\}$ is the set of countries' priority lists. It is assumed that all refugees deem all countries acceptable and priorities range over all refugees, so $E=R \times C$. The definition of a matching is equivalent to that in the CA model.

Priority rankings are usually generated through a point system. If two applicants have identical points, the priority ranking may be determined through a lottery or continuous factors. In the context of the refugee match, it seems plausible to give a refugee who has been waiting longer for transfer more points in all countries' rankings than to a refugee with less waiting time spent, other things being equal; so waiting time since registration in the system could be used as a continuous variable to break non-strict priorities. ${ }^{13}$

(ST) is in SC-instances usually interpreted as elimination of justified envy [49], but, in the context of asylum, the term elimination of justified grievance may appear more appropriate. If a refugee does not get matched to her most preferred destination and the matching satisfies (ST), then she has a

13 Depending on the context, refugees could be registered in member states of the system or hotspots (reception centres in frontline states within the system), in camps external to the member states of the system, or even in diplomatic missions such as embassies in the region of origin [50]. 
lower priority in that country than all the refugees matched to it and, hence, there is no ground for grievance. Deferred acceptance algorithms are applicable to SC-instances, and produce matchings that satisfy (ST). Let $\mu^{R}$ be the algorithm equivalent to $\mu^{C}$ but with the roles switched: the refugees propose and the countries accept the proposals in each step of the refugees with the highest priorities up to filling the countries' quotas. $\mu^{R}$ is typically preferred to $\mu^{C}$ in the SC model in which only refugees' welfare is taken into account because it produces the refugee-optimal stable matchings. Moreover, it is strategy-proof for refugees and thus strategy-proof tout court in a model in which countries are assumed not to strategise. ${ }^{14}$

An immediate normative problem that arises when applying the SC model to the distribution of asylum is that in this model, stability does not imply efficiency [49]. The following example from [36] illustrates this.

Example 2. There are three refugees, $r_{1}, r_{2}, r_{3}$, and three countries $c_{1}, c_{2}, c_{3}$ with $q_{1,2,3}=1$. The refugees' preferences and priorities are specified in Table 2.

Table 2. Refugees' preferences and priorities in Example 2.

\begin{tabular}{c|c}
\hline $\boldsymbol{P r i}$ & $\boldsymbol{P}$ \\
\hline$r_{1} \succ_{c_{1}} r_{3} \succ_{c_{1}} r_{2}$ & $c_{2} \succ_{r_{1}} c_{1} \succ_{r_{1}} c_{3}$ \\
$r_{2} \succ_{c_{2}} r_{1} \succ_{c_{2}} r_{3}$ & $c_{1} \succ_{r_{2}} c_{2} \succ_{r_{2}} c_{3}$ \\
$r_{2} \succ_{c_{3}} r_{1} \succ_{c_{3}} r_{3}$ & $c_{1} \succ_{r_{3}} c_{2} \succ_{r_{3}} c_{3}$ \\
\hline
\end{tabular}

The unique stable matching is $\left(\left(r_{1}, c_{1}\right),\left(r_{2}, c_{2}\right),\left(r_{3}, c_{3}\right)\right)$. It is Pareto-dominated by a matching where $r_{1}$ and $r_{2}$ switch their countries: $\left(\left(r_{1}, c_{2}\right),\left(r_{2}, c_{1}\right),\left(r_{3}, c_{3}\right)\right)$. This matching is not stable because $\left(r_{3}, c_{1}\right)$ forms a blocking pair.

Is asylum a context in which complete elimination of justified grievance should be ranked before efficiency, or vice versa? This depends on which interpretation of priorities is deemed appropriate in this context. Following [49], if the interpretation ought to be, "a refugee of higher priority in a country is entitled to asylum in that country before a refugee with lower priority", then we obtain elimination of justified grievance because there cannot be blocking pairs. If priorities are interpreted in a weaker sense and can be violated, exchanges as in Example 2 are possible which achieve efficient matchings but at the cost of producing blocking pairs.

While there may be some leeway for policy makers to decide which criterion to prioritise (cf. [7]), we anticipate that (ST) is important for the refugee match and normatively called for even if this leads to some efficiency loss. In the example, the efficient matching assigns $r_{3}$ to her least preferred country even though she has higher priority in her first-choice country, $c_{1}$, than $r_{2}$ who is assigned to it. Thus, the switch can be deemed unfair against $r_{3}$ because it causes $r_{3}$ to have justified grievance. (ST) blocks such unfair switches. This suggests that the elimination of justified grievance can be interpreted as a condition of fairness, whereas efficiency can be interpreted as a utilitarian criterion. However, it is a trimmed utilitarian criterion that only takes into account the welfare of one side of the market. If switches are possible as in the example, then countries could well complain by asking, "why are priorities even collected in the first place", and refuse to accept matches that are a result of such switches. (ST), on the other hand, achieves fairness not only among refugees but also towards countries because their priorities for refugees are respected.

14 The importance of strategy-proofness in the context of locally matching refugees is discussed in [6,9]. We should emphasise that it is only when we insist on strategy-proofness that there is a drastic tradeoff between efficiency and stability in the SC model; there is no such tradeoff when countries strategise because stable outcomes are efficient. See, e.g., [51]; we thank an anonymous referee for raising this point. 
As mentioned in Section 3, in many contexts fairness also contributes to the thickness of markets, giving agents incentives to participate in the system. In many contexts, if (ST) is violated, then the lack of fairness leads agents to rematch and finally, to an unravelling of the system. In our context, agents could be forced to participate in the system, and rematchings could perhaps be made impossible (cf. [7]). Note also that of course fairness cannot prevent illegal secondary movements. Nevertheless, a lack of fairness would likely lead to frustration with the redistribution system, which may, in turn, reinforce incentives to engage in illegal movement to countries other than the one matched to, or to vanish from the system altogether after learning about the matched destination country. Moreover, if countries' priorities are public information, then it is relatively easy for refugees to check whether they are being treated unfairly. They would just need to ask others about their priorities and check whether they are matched to a more preferred country. Such information flows can be expected to be particularly high in the important stage when refugees are waiting in a hotspot or camp for their relocation, and when it is crucial that they have confidence in the fairness of the system. Finally, there may also be practical arguments that (ST) should be prioritised over efficiency. If justified grievance is not completely eliminated, then there may be legal appeals from individuals who have a justified grievance.

\section{Discussion and Objections}

The desiderata (ST), (MC), and (COM) can be jointly satisfied if priorities can be agreed to be imposed in a certain way. Since it is assumed that everyone finds everyone else acceptable, (ST) and (MC) can be mutually satisfied, and deferred acceptance algorithms solve for stable matchings of maximum cardinality (the argument in Section 3 extends to this case). Moreover, priorities can be formulated that satisfy (COM), and thus the two problems encountered in the previous section can be resolved in the SC model. First, criteria must be agreed on for priorities that are acceptable. For example, it seems reasonable that countries be allowed to prioritise refugees that speak their language [7]. Some countries may still be keen to prioritise refugees on non-neutral properties such as religion; this is why it is crucial to clearly determine which types of priorities are acceptable and which are not. Doing so requires countries to give public reasons for the imposition of priority structures, and possibly mediation by a confederation-level institution. This would also prevent countries from being strategic, thereby adapting to the rules of the SC model.

Second, in addition to the specific needs of the refugees, relational factors between different host countries can be taken into account so as to avoid the danger of favouritism due to homogeneity. In the example where all refugees prefer country $H I$ to country $L O$, suppose $H I$ has a stronger economy than $L O$, as measured in GDP per capita. Suppose, moreover, that all refugees are workers with identical skills but half of them, $r_{51}-r_{100}$, are war-affected and unable to work. For fairness reasons among the countries, humanitarian factors could be given a higher priority in $\mathrm{HI}$ and economic factors (such as integrability into the labour market) a higher priority in $L O$, thus matching overproportionally many refugees from $r_{51}-r_{100}$ to $H I$ and overproportionally many refugees from $r_{1}-r_{50}$ to $L O$. This is again a process that calls for negotiation and mediation by a higher-level institution.

If priorities are imposed as described above, (MC), (ST), and (COM) can be jointly satisfied using deferred acceptance algorithms in the SC model. This model should thus be preferred to the CA model in the context of asylum. However, there is a counterargument: this comes at the price of treating asylum places as objects to be consumed by refugees. If a supranational institution is involved in the decision as to which types of priorities are acceptable and which are not, national policy makers may receive the impression that their national sovereignty is threatened under this model. On the face of it, it seems more realistic to model countries as agents with preferences because their governments clearly have preferences on issues of immigration. However, if the CA model appears more attractive to national governments than the SC model, it may be difficult in practice to impose the latter as an asylum policy whenever countries can voluntarily choose to participate in the system or have 
legislative co-determination. ${ }^{15}$ This may, the objection goes, provide a justified reason for why the EU allows countries to express their preferences over refugees in the first place.

To counter this objection, remember what the European Commission seeks to achieve by allowing countries to express preferences over refugees: to "facilitate their integration into the Member State of relocation". However, because of her private information, a refugee herself knows best where she will thrive; namely, "refugees go and integrate where they have family, where they have community, or where they think they can support themselves-in that order" ${ }^{16}$ It can be assumed that this is also the member states' primary goal. However, for this objective, countries interested in their integration will share refugees' preferences to pool their families and communities and to integrate them into the labour market. The SC model achieves this by collecting refugees' preferences and allowing countries to prioritise certain groups of refugees along neutral properties.

An even more important response to the objection is that the mandate for asylum should indeed be handed from countries to higher-level institutions, and that one should gather public support for this view. The protection of refugees is a public good, and, as such, suffers from insufficient supply from the countries' collective perspective $[3,7,8]$. An effective way to provide a supply of this good which is more consistent with its social desirability is to move the mandate to a superordinate government [40]. The other side of the coin is that this means to a certain extent depriving the countries of the mandate. This policy would be contrary to the EU's relocation mechanism, which seeks to achieve good matchings by taking into account countries' (but not refugees') preferences. However, as we have seen, problems abound with this mechanism. Moreover, the EU relocation system is similar to the CA-model in that countries' preferences are taken into account, and indeed suffers from similar problems this model would bring about. In particular, what the Commission calls an "incorrect use of preferences" - i.e., a violation of (COM) — would likely be shared in both systems. If this is true, the malfunctioning of the current system may be seen as evidence against implementing a CA-model.

A supranational mandate for the asylum system has additional advantages. Importantly, it permits a consistent definition of what counts as a justified asylum claim. A system that takes refugees' preferences into account is more attractive for refugees than a system that does not. Such a system can thus be expected to increase the demand for asylum. However, countries usually have an interest in narrowing down the market, rather than provoking a bigger run on asylum. An effective way to prevent this is to apply a clear-cut definition for the identification of justified asylum claims. However, this is difficult to agree on by single states with diverse standards for asylum. In a nutshell, we need a "communitarised" asylum system [50]. The SC but not the CA model takes a step in this direction.

\section{Conclusions}

Policy makers are increasingly interested in the question of which refugees to provide with asylum, in addition to the question of how many. The fact that mechanisms for distributing refugees can be designed in different ways gives rise to novel normative considerations. Reflecting on these has been the aim of this paper.

Some distribution mechanisms, such as the relocation mechanism in effect in the EU, seek to achieve good matches by taking countries' or refugees' preferences into account. We have argued that doing so may reduce the number of refugees matched if refugees may declare countries unacceptable or vice versa. However, to require that refugees accept any possible match presupposes that each refugee's rights be respected in all countries within the system-even in countries where they do not end up living.

15 This is the case in the EU: in the context of resettlements participation is voluntary and in the context of relocations participation is obligatory but countries have legislative co-determination through the Council.

16 The CEO of the refugee resettlement agency Hebrew Immigrant Aid Society (HIAS), quoted in [41]. In a similar vein, Rapoport [52]: "numerous studies show that the best indicator of future integration of migrants is the preference they express for a particular country". 
Second, we argued that national governments should not express preferences over refugees. Instead, priorities for refugees should be imposed according to humanitarian factors and fairness considerations among the countries within the system. We then argued that fairness is normatively called for and may in the context of distributing asylum beat efficiency considerations.

In terms of matching theory, we identified several reasons why asylum should not be modelled as a College Admissions but as a School Choice problem. Results from matching theory also helped to identify some of the problems that occur in the EU's relocation mechanism. For example, the fact that the mechanism does not systematically take refugees' preferences into account leads to unstable matchings and thereby violates fairness, which can be seen as a minimal condition for content. We hope to have shown that matching theory provides important tools for allocation problems in which agents' preferences matter and, thus, for numerous problems of distributive justice.

Our aims have been normative: to reflect on the conditions under which it is a desirable policy to take preferences into account, and whose preferences to take into account. More technical work remains to be done for market designers, for example to design fair mechanisms for matching refugees who migrate as families, and to investigate how relocation processes could be accelerated. Moreover, more work remains to be done for policy makers, to impose fairer asylum policies by drawing on both matching systems and on the kinds of normative considerations that have been proposed here.

Acknowledgments: I thank Jason Alexander, Luc Bovens, Katarina Cechlarova, Jurgis Karpus, Bryan Roberts, Katie Steele, Alex Teytelboym, and Nicolas Wuethrich for helpful comments and suggestions on earlier versions of the paper. Thanks also to the editor and anonymous referees of this journal for their help and ideas for improvement. Many thanks to the Kiel Institute for the World Economy (IfW), especially Matthias Lücke, for a research visit and the opportunity to present in the IfW's Behavioral Economics Seminar.

Conflicts of Interest: The author declares no conflict of interest.

\section{Abbreviations}

The following abbreviations are used in this manuscript:

$$
\text { stability }
$$

(MC) maximum cardinality

(COM) compliance

CA model College Admissions model

SC model School Choice model

$\mu^{R / C} \quad$ Deferred acceptance algorithm with refugees/countries proposing

\section{References}

1. European Commission. Proposal for a Regulation of the European Parliament and of the Council. COM(2015) 450 Final. 2015. Available online: http://ec.europa.eu/dgs/home-affairs/what-we-do/ policies/european-agenda-migration/proposal-implementation-package/docs/proposal_for_regulation_ of_ep_and_council_establishing_a_crisis_relocation_mechanism_en.pdf (accessed on 22 September 2017).

2. Bansak, K.; Hainmueller, J.; Hangartner, D. How economic, humanitarian, and religious concerns shape European attitudes toward asylum seekers. Science 2016, 354, 217-222.

3. Fernández-Huertas Moraga, J.; Rapoport, H. Tradable immigration quotas. J. Public Econ. 2014, 115, 94-108.

4. Fernández-Huertas Moraga, J.; Rapoport, H. Tradable Refugee-admission quotas and EU asylum policy. CESifo Econom. Stud. 2015, 61, 638-672.

5. Fernández-Huertas Moraga, J.; Rapoport, H. Tradable Refugee-admission Quotas (TRAQs), the Syrian Crisis and the new European Agenda on Migration. IZA J. Eur. Labor Stud. 2015, 4, 23.

6. Jones, W.; Teytelboym, A. The local refugee match: Aligning refugees' preferences with the capacities and priorities of localities. J. Refug. Stud. 2017, doi:10.1093/jrs/fex022.

7. Jones, W.; Teytelboym, A. The international refugee match: A system that respects refugees' preferences and the priorities of states. Refug. Surv. Q. 2017, 1036, 84-109.

8. Jones, W.; Teytelboym, A. Matching systems for refugees. JMHS 2017, 5, 667-681. 
9. Delacrétaz, D.; Kominers, S.D.; Teytelboym, A. Refugee resettlement. Unpublished, 2016. Available online: http:/ / www.t8el.com/jmp.pdf (22 September 2017).

10. Andersson, T.; Ehlers, L. Assigning Refugees to Landlords in Sweden: Efficient Stable Maximum Matchings; Working Paper; Department of Economics, School of Economics and Management, Lund University: Lund, Sweden, 2017; Volume 18.

11. Shacknove, A.E. Who is a refugee? Ethics 1985, 95, 274-284.

12. Bartsch, A.; Bovens, L. Towards a Fairer Distribution of Asylum Seekers. Voxeurop 2016. Available online: http://www.voxeurop.eu/en/content/article/5041680-towards-fairer-distributionasylum-seekers (accessed on 22 September 2017).

13. Grech, P. Undesired Effects of the European Commission's Refugee Distribution Key; Negotiation and Conflict Management Research Paper Series; ETH Zürich: Zürich, Switzerland, 2016.

14. Council of the European Union. Council Decision 2015/1523 Establishing Provisional Measures in the Area of International Protection for the Benefit of Italy and Greece. 2015. Available online: http:/ / eur-lex.europa. eu/legal-content/EN/TXT/PDF/?uri=CELEX:32015D1523\&from=EN (22 September 2017).

15. Council of the European Union. Council Decision 2015/1601 Establishing Provisional Measures in the Area of International Protection for the Benefit of Italy and Greece. 2016. Available online: http:/ / ec.europa.eu/dgs/home-affairs/what-we-do/policies/european-agenda-migration/proposalimplementation-package/docs/20160321/provisional_measures_area_international_protection_benefit_ italy_and_greece.pdf (22 September 2017).

16. European Commission. First Report on Relocation and Resettlement, COM(2016) 165 Final. Communication from the Commission to the European Parliament, the European Council and the Council. 2016. Available online: http: / / ec.europa.eu/dgs/home-affairs/what-we-do/policies/european-agenda-migration/proposalimplementation-package/docs/20160316/first_report_on_relocation_and_resettlement_en.pdf (accessed on 22 September 2017).

17. European Commission. Sixth Report on Relocation and Resettlement. Communication from the Commission to the European Parliament, the European Council and the Council. 2016. Available online: http:/ / ec.europa.eu/dgs/home-affairs/what-we-do/policies/european-agenda-migration/proposalimplementation-package/docs/20160928/sixth_report_on_relocation_and_resettlement_en.pdf (accessed on 22 September 2017).

18. European Commission. Fifth Report on Relocation and Resettlement. Communication from the Commission to the European Parliament, the European Council and the Council. 2016. Available online: http:/ / ec.europa.eu/dgs/home-affairs/what-we-do/policies/european-agenda-migration/proposalimplementation-package/docs/20160713/fifth_report_on_relocation_and_resettlement_en.pdf (accessed on 22 September 2017).

19. European Commission. Member States' Support to Emergency Relocation Mechanism. (As of 21 July 2017). Available online: https://ec.europa.eu/home-affairs/sites/homeaffairs/files/what-we-do/ policies/european-agenda-migration/press-material/docs/state_of_play_-_relocation_en.pdf (accessed on 22 September 2017).

20. Gale, D.; Shapley, L.S. College admissions and the stability of marriage. Am. Math. Mon. 1962, 1069, 9-15.

21. Klaus, B.; Manlove, D.F.; Rossi, F. Matching under preferences. In Handbook of Computational Social Choice; Brandt, F., Conitzer, V., Endriss, U., Lang, J., Procaccia, A.D., Eds.; Cambridge University Press: Cambridge, UK, 2016; pp. 333-355.

22. Roth, A.E. The evolution of the labor market for medical interns and residents: A case study in game theory. J. Political Econ. 1984, 92, 991-1016.

23. Roth, A.E. What have we learned from market design? In The Handbook of Market Design; Vulkan, N., Roth, A.E., Neeman, Z., Eds.; Oxford University Press: Oxford, UK, 2013; pp. 7-50.

24. Roth, A.E.; Sotomayor, M.A. Two-Sided Matching: A Study in Game-Theoretic Modeling and Analysis; Cambridge University Press: Cambridge, MA, USA, 1990.

25. Sönmez, T. Manipulation via capacities in two-sided matching markets. J. Econ. Theory 1997, 77, 197-204.

26. Coles, P.; Cawley, J.; Levine, P.B.; Niederle, M.; Roth, A.E.; Siegfried, J.J. The job market for new economists: A market design perspective. J. Econ. Perspect. 2010, 24, 187-206.

27. Rettman, A. Slovakia Filing Case against EU Migrant Relocation. EU Observer. 2015. Available online: https: / / euobserver.com/justice/130499 (accessed on 22 September 2017). 
28. Court of Justice of the European Union. Judgment in Joined Cases C-643/15 and C-647/15 Slovakia and Hungary v Council. Press Release No 91/17. 2017. Available online: https:/ / curia.europa.eu/jcms/upload/ docs/application/pdf/2017-09/cp170091en.pdf (accessed on 22 September 2017).

29. International Communications Office, Cabinet Office of the Prime Minister. PM Orbán: European Court Decision Won't Change Hungary's Immigration Policies. 2017. Available online: http://abouthungary. $\mathrm{hu} /$ news-in-brief/pm-orban-european-court-decision-wont-change-hungarys-immigration-policies / (accessed on 22 September 2017).

30. Fragiadakis, D.; Iwasaki, A.; Troyan, P.; Ueda, S.; Yokoo, M. Strategyproof matching with minimum quotas. ACM Trans. Econom. Comput. 2015, 4, 6.

31. Parfit, D. Equality and priority. Ratio 1997, 10, 202-221.

32. Parfit, D. Another Defence of the priority view. Utilitas 2012, 24, 399-440.

33. Rawls, J. A Theory of Justice; Harvard University Press: Harvard, MA, USA, 1971.

34. Harsanyi, J.C. Essays on Ethics, Social Behavior and Scientific Explanation; D. Reidel Publ. Co.: Dordrecht, The Netherlands, 1976.

35. UNHCR. Projected Global Resettlement Needs 2017. 2016. Available online: http://reliefweb.int/sites/ reliefweb.int/files/resources/575836267.pdf (accessed on 22 September 2017).

36. Roth, A.E. The economics of matching: Stability and incentives. Mathe. Oper. Res. 1982, 7, 617-628.

37. Abdulkadiroğlu, A.; Pathak, P.A.; Roth, A.E. Strategy-proofness versus efficiency in matching with indifferences: Redesigning the NYC high school match. Am. Econ. Rev. 2009, 99, 1954-1978.

38. Erdil, A.; Ergin, H. What's the matter with tie-breaking? improving efficiency in school choice. Am. Econ. Rev. 2008, 98, 669-689.

39. Miller, D. Immigrants, nations, and citizenship. J. Political Philos. 2008, 16, 371-390.

40. Lücke, M. The EU needs the mandate to fund and administer the asylum system. In Migrants Knocking on Europe's Doors—Solutions for a Coherent Response to Irregular Immigration; Snower, D.J., Ed.; GES Special Report; GES: Kiel, Germany, 2016; pp. 6-7.

41. Roth, A.E. Migrants Aren't Widgets. Politico. 2015. Available online: http://www.politico.eu/article/ migrants-arent-widgets-europe-eu-migrant-refugee-crisis / (accessed on 22 September 2017).

42. Katz, B.; Noring, L.; Garrelts, N. Cities and Refugees: The German Experience. Brookings. 2016. Available online: https://www.brookings.edu/research/cities-and-refugees-the-german-experience/ ?utm_campaign=Brookings+Brief\&utm_source=hs_email\&utm_medium=email\&utm_content=34709340 (accessed on 22 September 2017).

43. Eurostat. News Release 217/2015. 2015. Available online: http://ec.europa.eu/eurostat/ documents /2995521/7105334/3-10122015-AP-EN.pdf/04886524-58f2-40e9-995d-d97520e62a0e (accessed on 22 September 2017).

44. Eurostat. News Release 44/2016. 2016. Available online: http://ec.europa.eu/eurostat/documents/ 2995521/7203832/3-04032016-AP-EN.pdf/790eba01-381c-4163-bcd2-a54959b99ed6 (accessed on 22 September 2017).

45. Amnesty International. Urgent Action: Hungary violates human rights of refugees. UA 2015, 202.

46. UNHCR. Hungary Violating International Law in Response to Migration Crisis: Zeid. 2015. Available online: http:/ / www.ohchr.org/en/NewsEvents/Pages/DisplayNews.aspx?NewsID=16449\&LangID=E (accessed on 22 September 2017).

47. Fletcher, M. I'm a Conservative, but this Asylum Seekers Comic Is Disgusting. AusOpinion, Reprinted in The Guardian Online. 2014. Available online: https:/ /www.theguardian.com/commentisfree/2014/feb/13/ asylum-seekers-graphic-campaign (accessed on 22 September 2017).

48. Roth, A.E. Repugnance as a constraint on markets. J. Econ. Perspect. 2007, 21, 37-58.

49. Abdulkadiroğlu, A.; Sönmez, T. School Choice: A Mechanism Design Approach. Am. Econ. Rev. 2003, 93, 729-747.

50. Ademmer, E.; Barsbai, T.; Lücke; M.; Stöhr, T. 30 Years of Schengen: Internal Blessing, External Curse? In Kiel Policy Brief; IfW: Kiel, Germany, 2015; Volume 88. 
51. Kesten, O. School choice with consent. Q. J. Econ. 2010, 125, 1297-1348.

52. Rapoport, H. A Fair and Efficient European Response to the Refugee Crisis. 2016. Available online: http:/ / www.parisschoolofeconomics.eu/en/economics-for-everyone/for-a-wider-audience/a-wordfrom/hillel-rapoport-a-fair-and-efficient-european-response-to-the-refugee-crisis/ (accessed on 22 September 2017). 